\title{
DESIGN AND PERFORMANCE VERIFICATION OF NEWLY DEVELOPED DISPOSABLE STATIC DIFFUSION CELL FOR DRUG DIFFUSION/PERMEABILITY STUDIES
}

\author{
ANKIT KUMAR YADAV ${ }^{1}$, VARUN GARG ${ }^{1}$, MONICA GULATI ${ }^{1}$, PARIKSHIT BANSAL ${ }^{2}$, KOMPAL BANSAL ${ }^{2}$, \\ PUNEET KAUR $^{3}$, SACHIN KUMAR SINGH ${ }^{1 *}$, AMIT MITTAL ${ }^{1}$, RAKESH NARANG ${ }^{1}$, BIMLESH KUMAR ${ }^{1}$, NARENDRA \\ KUMAR PANDEY ${ }^{1}$, SHEETU WADHWA ${ }^{1}$, GOPAL LAL KHATIK ${ }^{1}$, MAYUKH BANERJEE ${ }^{1}$, SOUVIK MOHANTA ${ }^{1}$, \\ SHUBHAM SINHA ${ }^{1}$, JIVAN JYOTI ${ }^{1}$, SANANDA SOM ${ }^{1}$, BHUPINDER KAPOOR ${ }^{1}$, SAURABH SINGH ${ }^{1}$
}

\author{
${ }^{1}$ Department of Pharmacy, School of Pharmaceutical Sciences, Lovely Professional University, Phagwara - 144411, Punjab, India. \\ ${ }^{2}$ Excellion Innovations and Inventions Pvt., Ltd., (EXII) Pvt. Ltd, 5568, Sector 38-West, Chandigarh - 160 014, India. ${ }^{3}$ Washington State \\ University, College of Pharmacy, Spokane, WA, USA \\ Email: singhsachin23@gmail.com
}

Received: 05 April 2018, Revised and Accepted: 11 July 2018

ABSTRACT

Objectives: The present study describes a disposable static diffusion cell for in vitro diffusion studies to achieve better results as compared to well existing Franz diffusion cell (FDC) in terms of the absence of bubbles, variable receptor compartment, ease of handling, and faster results.

\begin{abstract}
Materials and Methods: The cell consists of a cup-shaped donor compartment made of semi permeable that could be either cellophane membrane or, animal skin fitted to a rigid frame, which is supported on a plastic plate that contains a hole for the sample withdrawal. The receptor compartment is a separate unit, and it could be any container up to $500 \mathrm{ml}$ volume capacity. The most preferred receptor compartment is glass beaker. In the present study, goatskin was used as semi-permeable membrane and verification of its performance was carried out through diffusion studies using gel formulations of one each of the four-selected biopharmaceutical classification system (BCS) class drugs. Metronidazole, diclofenac sodium, fluconazole, and sulfadiazine were used as model drugs for BCS Class I, II, III, and IV, respectively.
\end{abstract}

Results: The newly developed diffusion cell (NDDC) was found to provide faster and more reproducible results as compared to FDC. At the time interval of $24 \mathrm{~h}$, the cell was found to exhibit a higher diffusion of metronidazole, diclofenac sodium, fluconazole, and sulfadiazine by $0.65,0.65,0.32$, and 0.81 folds, respectively. The faster release obtained with NDDC was attributed to a larger surface area of skin as compared to that in FDC.

Conclusion: It was concluded that better reproducibility of results could be achieved with NDDC.

Keywords: Newly developed diffusion cell, Franz diffusion cell, Biopharmaceutical classification system, Metronidazole, Diclofenac sodium, Fluconazole, Sulfadiazine.

(c) 2018 The Authors. Published by Innovare Academic Sciences Pvt Ltd. This is an open access article under the CC BY license (http://creativecommons. org/licenses/by/4. 0/) DOI: http://dx.doi.org/10.22159/ajpcr.2018.v11s2.28506

\section{INTRODUCTION}

Among the drug delivery systems, transdermal drug delivery offers avoidance of first-pass metabolism, decreased toxicity, fewer side effects, as well as greater patient compliance [1,2]. To evaluate the performance of prepared transdermal formulation in vitro static diffusion cells are used. This diffusion study helps the scientists to understand the relationship between skin, drug, and formulation $[3,4]$. This further helps to optimize the formulation and process variables for optimizing the formulation as well as help to assess the toxicity of the drug [5-8]. The most common technique for measuring dermal absorption in vitro is the application of the test substance in an appropriate formulation to the surface of a skin sample, which is mounted as a barrier between the donor compartment and receptor compartment of a diffusion cell [9]. Diffusion cells may be of static [3] or flow-through [10]. Static diffusion cells sample this chamber and replace with new perfusate at each time point. Flow-through cells use a pump to pass perfusate through the receptor chamber and collect flux by repeatedly collecting perfusate [9]. Static diffusion cells can be subdivided on the basis of the skin orientation: The membrane can be placed horizontally or vertically. The majority of skin absorption studies are conducted using horizontal cells, with the skin surface open to the air. The use of vertical (or side-by-side) cells is more common when evaluating drug delivery systems such as sonophoresis, iontophoresis, or electroporation and requires immersion of both surfaces of the skin preparation, which may result in excessive hydration and possibly skin damage [11].
One of the most widely used static designs for studying in vitro permeation is the Franz diffusion cell (FDC) [12]. FDC comprises a donor chamber, an upper chamber through which the drug formulation to be studied/tested is placed into the device/cell. The chamber is attached to a flat ground glass joint. Another component is semipermeable membrane which is the "functional" part of the device and comprises. In general, regenerated cellulose membrane is used, due to good permeability and resistance to various organic solvents/buffers. The membrane is placed horizontally between the donor chamber and receptor chamber and held in place by means of a clamp. The lower part of FDC is receptor chamber, which contains buffer/water, into which the drug diffuses. The chamber is surrounded by a "water jacket" through which heated water is circulated by means of a heater/circulator and helps to maintain the temperature of buffer/water inside the receptor chamber, constant simulating the body temperature. To measure the rate of drug diffusion across the semi-permeable membrane, from the "donor chamber" into the "receptor chamber," sampling of the solution inside the receptor chamber has to be carried out, at regular time intervals. A "sampling port" is provided in the form of an "arm" through which the "solution" can be simply withdrawn with the help of a needle/syringe [3]. Water/buffer inside the receptor chamber is stirred gently by means of a stirring arrangement, which comprises a magnetic bar placed inside the receptor chamber. The assembly is then placed over a magnetic stirrer so that the bar rotates and helps to stir the solution. 
Although FDC is immensely popular and is considered the golden standard for performing drug permeation studies, it suffers from the following serious limitations of restricted sink volume, restricted membrane area, slow, cumbersome, and laborious handling and problem of air-bubbles.

Yang and Imbert (2008) and Yang and Imbert (2011) reported an improved static diffusion cell, in which a bubble-trap has been introduced, and the cell was compact. However, it still suffered from the limitation of a dedicated receptor compartment having a sidearm for sample collection and also having a very limited and fixed volume which cannot be altered [11,13]. In another study, Mohammad reported a static diffusion cell utilizing fresh corneas, for transcorneal drug penetration studies. It had means to create pressure within the chamber, to simulate intraocular pressure in the human eye of 20-22 $\mathrm{mm}$-Hg. The major limitation was that the cell was quite complicated, required use of fresh corneas involving sacrifice of animals and the entire assembly was of fixed size, restricting flexibility of experimental design and also the sink volume [14]. Joseph et al. reported improved FDC for evaluation of gel formulations for topical drug delivery [15]. However, the basic limitations of the FDC, i.e., limited membrane area and restricted receptor chamber volume were not overcome. Castro et al. reported transdermal diffusion cell testing arrangement and methods but the basic component of FDC remained unchanged [16]. The size of the receptor chamber was also fixed, and the membrane surface area was also limited [16].

The present study describes a disposable static diffusion cell for in vitro diffusion studies to achieve better results as compared to well existing FDC in terms of the absence of bubbles, variable receptor compartment, ease of handling, and faster results. To check the effectiveness of newly designed diffusion cell (NDDC), drug from each biopharmaceutical classification system (BCS) class of drugs was selected, and their gel formulations were prepared. Their diffusion profiles were compared through goatskin using NDDC as well as FDC.

\section{MATERIALS AND METHODS}

\section{Materials}

Metronidazole, fluconazole, and sulfadiazine were procured from Jackson Laboratories (Pvt.) Ltd., Punjab, India. Diclofenac sodium was gifted by Rydberg Pharmaceutical, Dehradun, India. Hydroxypropyl methylcellulose (HPMC) K15M was gifted by Colorcon (Pvt.) Ltd., Bengaluru, India. Potassium dihydrogen orthophosphate, hydrochloric acid, and dimethylformamide were purchased from central drug house Pvt., Ltd., Mumbai, India. Sodium hydroxide pellets were purchased from Loba Chemie Pvt. Ltd., Mumbai, India. Triethanolamine was purchased from Molychem, Babu Genu Road, Mumbai, India. Triple distilled water was used throughout the study.

\section{Methods}

Preparation of gel formulation for permeation studies

A $1 \% \mathrm{w} / \mathrm{v}$ gel of the drugs, metronidazole, diclofenac sodium, fluconazole, and sulfadiazine were prepared individually using HPMC K15Mas gelling agent. The preparation was allowed to stand, permitting entrapped air to separate. Then, triethanolamine was added dropwise to neutralize the gel. The formula for the gel preparation is shown in Table 1.
Design of the novel static diffusion cell and its comparison with FDC

The presented diffusion cell is a disposable static diffusion cell made mainly from plastic. The improved cell and its various components are depicted in Fig. 1. The improved diffusion cell comprises the following parts:

\section{Donor chamber}

Unlike the FDC, where the donor chamber and the membrane are separate parts and need to be assembled, in new diffusion cell, the donor chamber, and membrane form an "integrated part" and no assembling is needed. The donor chamber comprises a plastic ring (1) to which is attached a membrane sac (2), such that the interior of the plastic ring and the open end of the membrane sac are in flow communication with each other. This semi-permeable membrane could be replaced by animal's skin or, any other cellular membrane. This enables easy holding and handling. Unlike the FDC where membrane is stretched across an opening, in the new cell, it is in the form of a "sac" attached to a hard rim. The drug formulation is applied inside the sac.

\section{Bi-functional disc}

Comprises a flat plastic plate having two apertures - a larger central aperture (4) and a smaller lateral aperture (5). The sac is simply placed over the rim of the central aperture and does not require any clamp to hold it. The sac dips into the solution in the receptor chamber. The smaller, laterally positioned aperture (5), acts as a sample collection port through which a pipette (9) is inserted for a sampling of solution (7) in the receptor chamber (6), for withdrawing the sample.

\section{Receptor chamber}

This is the lower chamber (6), which contains the medium (7) into which the drug diffuses. It is an ordinary glass beaker. It can be placed over a magnetic stirrer with a heating plate to maintain the medium at a constant temperature. The receptor chamber is thus not an essential part of the assembly and is separate. Depending on the solubility and permeability characteristics of the drug molecule (BCS class) and

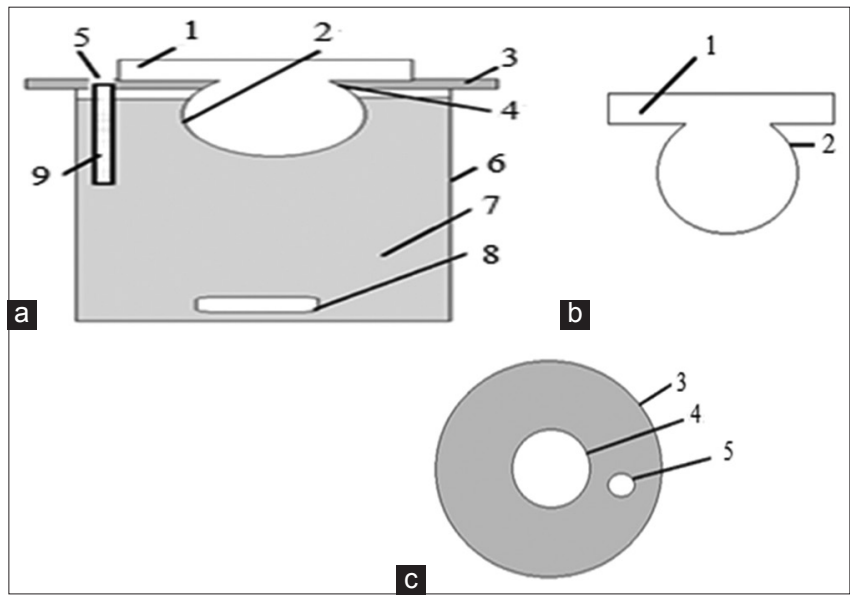

Fig. 1a: Fully assembled newly developed diffusion cell in operation, Fig. 1b: Integrated donor chamber (1) with permanently attached membrane sac (2), Fig. 1c: Bi-functional disc (3) with a central hole (4) and lateral hole (5)

Table 1: Composition of gel formulation

\begin{tabular}{llllllll}
\hline S. No & Name of drug & BCS class & Quality of drug (g) & pH 5.0 acetate buffer & DMF* & HPMC K15M & Purified water \\
\hline 1 & Metronidazole & I & 0.5 & 45 & - & 1 & Quantity sufficient to 50 ml \\
2 & Diclofenac & II & 0.5 & 45 & - & 1 & \\
3 & Fluconazole & III & 0.5 & 45 & - & 1 & \\
4 & Sulfadiazine & IV & 0.5 & 45 & 9 & 1 & \\
\hline
\end{tabular}

BCS: Biopharmaceutical classification system, HPMC: Hydroxypropyl methylcellulose 
the body compartment which is to be simulated, a beaker of suitable volume can be selected as the receptor compartment.

\section{Stirring arrangement}

This comprises a magnetic bar (8) placed inside the receptor chamber which stirs the solution at the required $\mathrm{rpm}$.

\section{Sampling arrangement}

Unlike the FDC where a "sampling port" is provided in the form of an "arm" through which the "solution" can be withdrawn with the help of a needle and syringe, sampling arrangement in the cell of the new design is quite different. The disc comprises a "hole" (5) through which a pipette (9) can be inserted, and the sample can be withdrawn. As a result, the problem of bubbles is altogether eliminated.

\section{Ex vivo diffusion studies using FDC}

Ex vivo diffusion study of prepared gel formulations was carried out using freshly isolated goat abdominal skin, collected from slaughterhouse in saline. The hairs of goatskin were removed using scissor followed by marketed hair remover. Skin was then washed with distilled water to remove the mucous and other adhered matrices. Additional fat layer was removed from the skin using scalpel blade. Skin of about $0.2 \mathrm{~mm}$ thickness and $3 \mathrm{~cm}$ length were mounted on FDC having a surface area of $1.79 \mathrm{~cm}^{2}$ and volume of $25 \mathrm{~mL}$. The skin was stabilized using acetate buffer ( $\mathrm{pH} 5.0$ ) in both, donor and receptor compartments with magnetic stirring for $30 \mathrm{~min}$. At the end of $30 \mathrm{~min}$, the existing buffers in both the compartments were replaced with fresh buffer. Prepared gel formulation (1 g) containing drug of different classes was placed individually on to the donor compartment. The study was carried out for $24 \mathrm{~h}$, and at predetermined time intervals, samples were withdrawn from the receptor compartment. Withdrawn samples were filtered through $0.45 \mu \mathrm{m}$ membrane filter and analyzed for drug concentration using ultraviolet (UV)-visible spectrophotometer at $315 \mathrm{~nm}$ for metronidazole, $276 \mathrm{~nm}$ for diclofenac sodium, $265 \mathrm{~nm}$ for fluconazole, and $258 \mathrm{~nm}$ for sulfadiazine, respectively. Each study was carried out in triplicate and mean data were recorded. The permeation profile was constructed by plotting amount of drug permeated per unit skin surface area $\left(\mu \mathrm{g} / \mathrm{cm}^{2}\right)$ versus time $(\mathrm{h})$. The steady state flux (Jss, mcg/ $\mathrm{cm}^{2} \mathrm{~h}$ ) was calculated from the slope of the linear portion of the plot using linear regression analysis [17].

The entire procedure for preparation of skin for diffusion studies using FDC is depicted in Fig. 2.

Skin permeation studies using newly developed diffusion cell (NDDC)

Skin permeation studies were performed on NDDC (effective surface diameter $7.4 \mathrm{~cm}$, volume $260 \mathrm{ml}$, area $11.618 \mathrm{~cm}^{2}$, Excellion Innovations Co., Ltd., India). The skin was brought to room temperature and mounted between the donor and receptor compartments of the diffusion cells where the epidermal faced upward and the dermal side faced downward. The residues were trimmed. Initially, the donor compartments were empty, and the receiver chamber was filled with degassed acetate buffer ( $\mathrm{pH}$ 5.0). The receptor fluid was stirred magnetically at a speed of $50 \mathrm{rpm}$, and the assembled apparatuses were adjusted and maintained at $32^{\circ} \mathrm{C}$ with the aid of digital thermo controller. After equilibration for $30 \mathrm{~min}$, the $1 \mathrm{~g}$ of prepared gels were applied on the skin sheet of donor compartment of NDDC. Samples were withdrawn at predetermined time intervals and replenished with $10 \mathrm{~mL}$ fresh degassed buffer. Prepared gel formulation ( $1 \mathrm{~g}$ ) containing drug of different classes was placed individually on to the donor compartment. The study was further followed as per the procedure mentioned for FDC. The experiments were repeated in triplicate and mean data were recorded. The scheme of preparation of skin for drug permeation studies using newly diffusion cell is shown in Fig. 3.

\section{Specificity studies}

To check the interaction of the drug with skin and the excipients used in the formulation, the study was conducted in which the drug was mixed

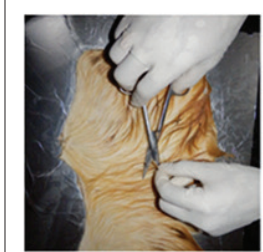

a

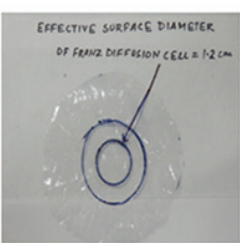

f

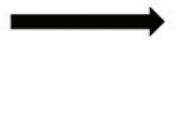

b
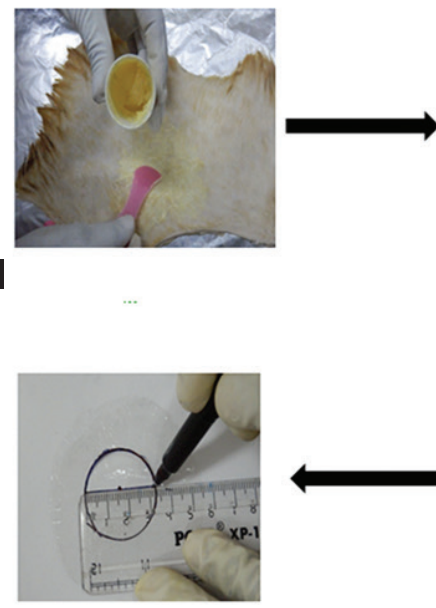

e

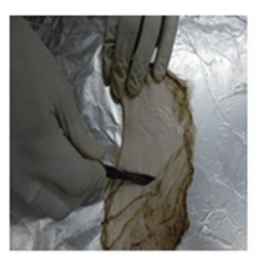

C

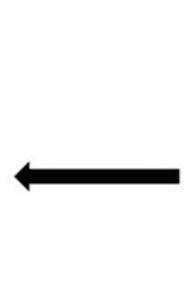

d

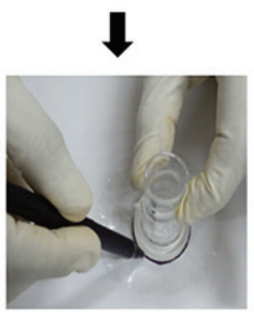

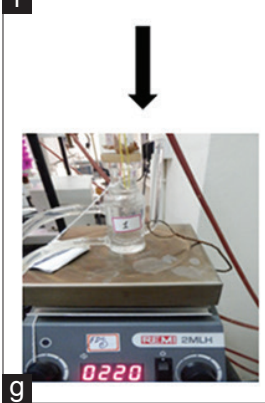

Fig. 2: Cutting of hair (a): Removal of hair using hair remover (b): Removal of fatty mass using scalpel (c): Measurement of diameter of semipermeable membrane used as donor compartment for Franz diffusion cell (FDC) (d-f): Application of gel to the donor compartment and conduct of diffusion study using FDC 


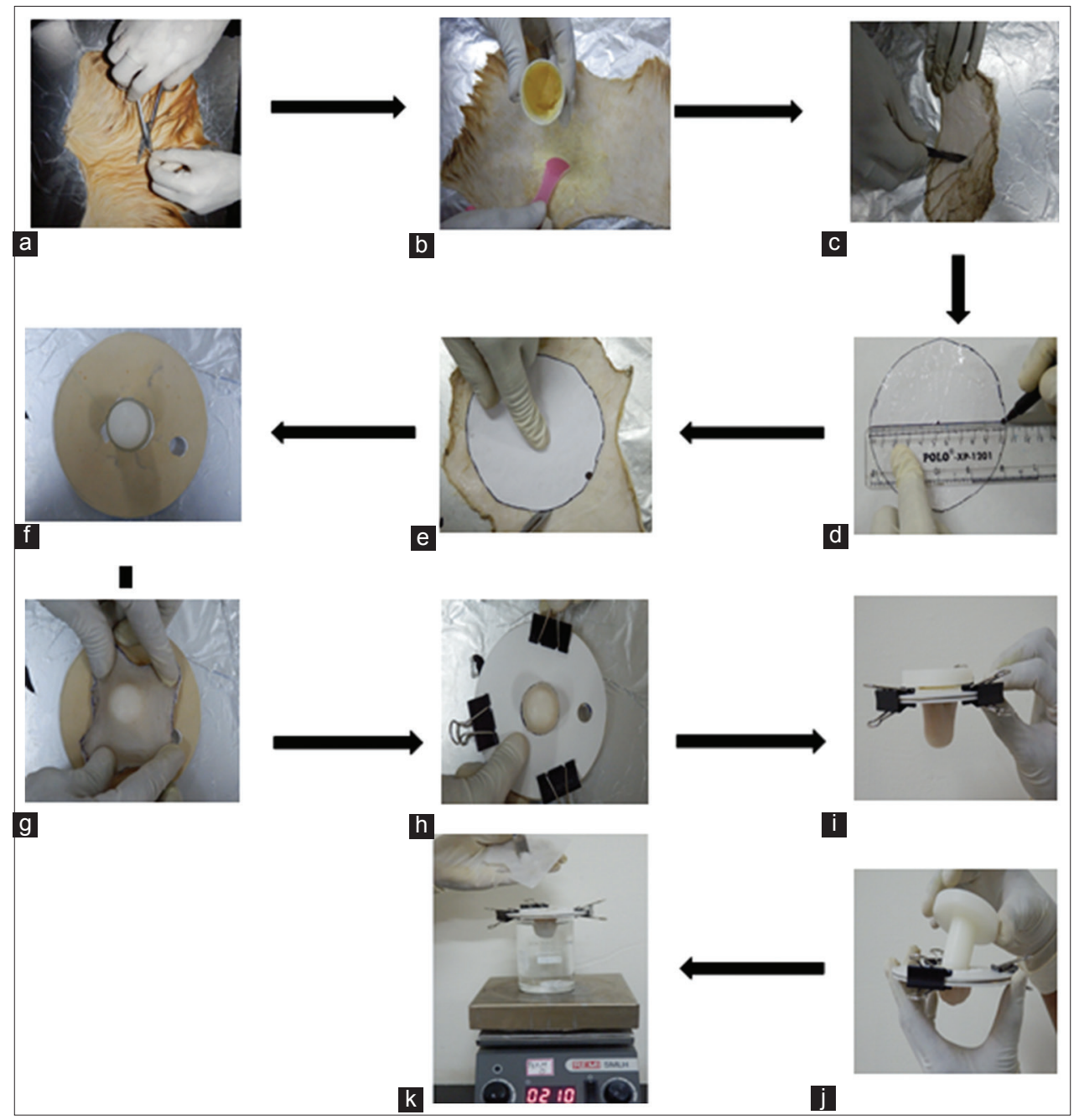

Fig. 3: (a): Removal of hair using hair remover (b): Removal of fatty mass using scalpel (c): Measurement of diameter of semipermeable membrane used as donor compartment for newly developed diffusion cell (d): Measurement of skin diameter exactly as that of semipermeable membrane (c): Mounting of skin for preparation of donor compartment (f-j): Application of gel to the donor compartment

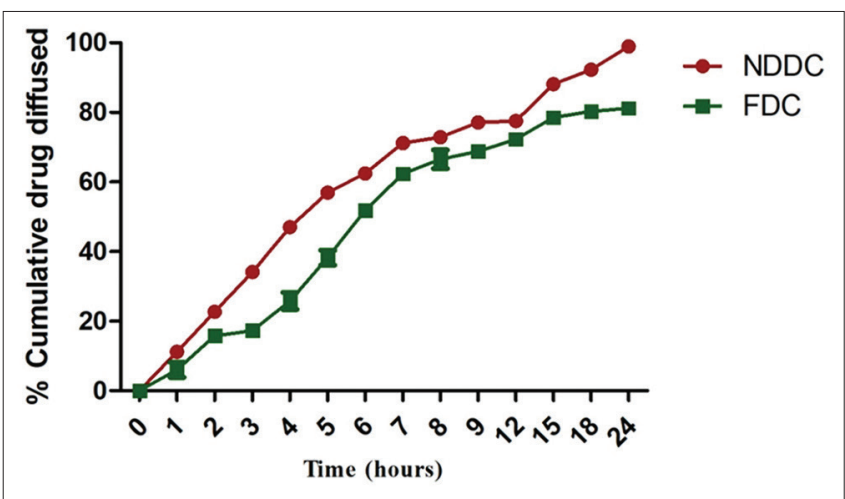

Fig. 4: Diffusion study of metronidazole

with skin homogenate and the excipients used in the formulation. Finally, pure drug solution, skin homogenate, drug solution containing skin homogenate, drug solution mixed with placebo solution, and placebo solution were scanned in UV spectrophotometer at the absorbance maxima of all the selected drugs.

\section{Statistical analysis of data}

All the data were statistically analyzed by analysis of variance using INSTAT 1 software. Results are quoted as significant where $P<0.05$.

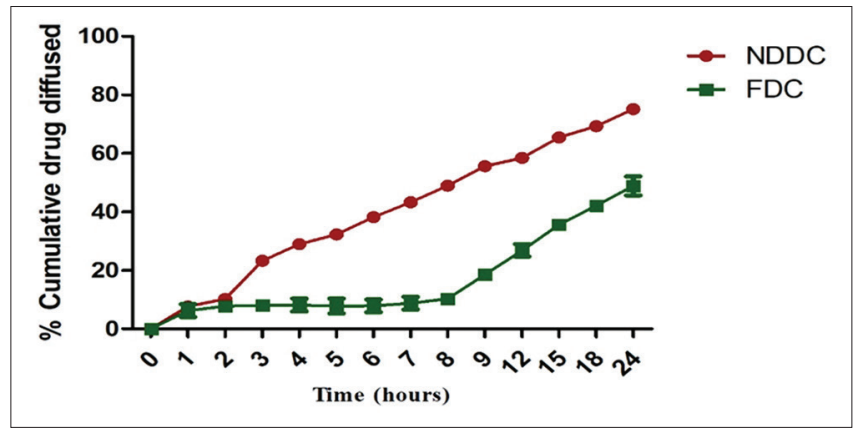

Fig. 5: Diffusion study of diclofenac sodium

Values of the coefficient of variation were calculated for each reading to have an idea about the reproducibility of results.

\section{RESULTS AND DISCUSSIONS}

Ex vivo skin permeation studies

The comparison of mean percentage cumulative drug release for metronidazole, diclofenac sodium, fluconazole, and sulfadiazine in FDC and novel diffusion cell is shown in Figs. 4-7. The mean percentage cumulative drug release after $24 \mathrm{~h}$ study for FDC was found to be $81.21 \%, 48.88 \%, 80.88 \%$, and $41.28 \%$ for metronidazole, diclofenac sodium, fluconazole, and sulfadiazine, respectively. Whereas, with 
NDDC mean percentage cumulative drug release after $24 \mathrm{~h}$ study was found to be $98.96 \%, 75.14 \%, 95.14 \%$, and $61.14 \%$ for metronidazole, diclofenac sodium, fluconazole, and sulfadiazine, respectively. The

Table 2: Data showing $\mathrm{T} 50 \%$ drug release from gel formulation of different BCS class drugs using diffusion cell NDDC and FDC

\begin{tabular}{lll}
\hline \multirow{2}{*}{ Drug } & T50\% (h) & \\
\cline { 2 - 3 } & NDDC & FDC \\
\hline Metronidazole gel & 5.0 & 6.8 \\
Diclofenac sodium gel & 9.0 & - \\
Fluconazole gel & 5.0 & 8.0 \\
Sulfadiazine gel & 9.0 & - \\
\hline
\end{tabular}

NDDC: Newly developed diffusion cell, FDC: Franz diffusion cell

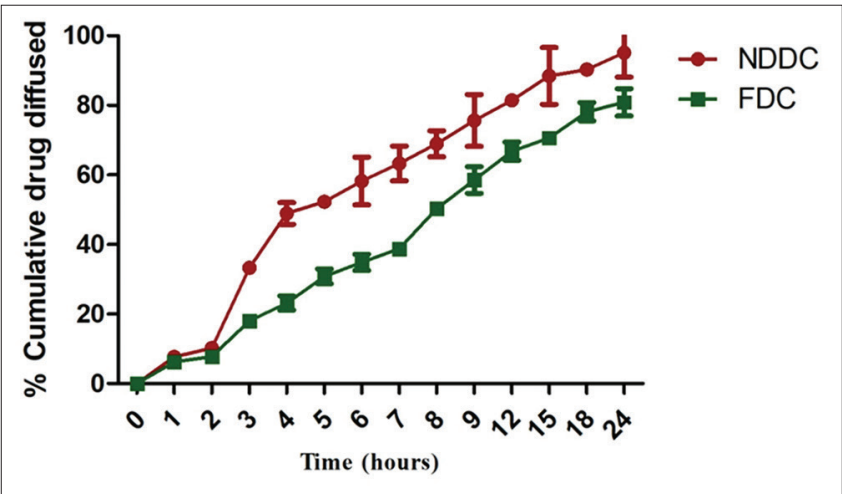

Fig. 6: Diffusion study of fluconazole

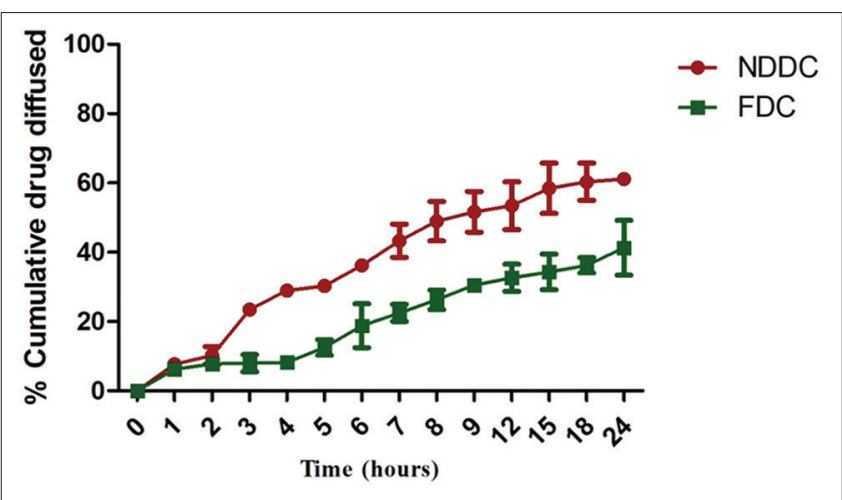

Fig. 7: Diffusion study of sulfadiazine
T50\% (time at 50\% drug got released) drug release was observed at $5 \mathrm{~h}, 9 \mathrm{~h}, 5 \mathrm{~h}$, and $9 \mathrm{~h}$ for metronidazole, diclofenac sodium, fluconazole, and sulfadiazine, respectively. However, the T50\% drug release was only observed for metronidazole $(6 \mathrm{~h})$ and fluconazole $(8 \mathrm{~h})$ in any of the studies carried out using FDCs even after $24 \mathrm{~h}$. The T50\% drug release is shown in Table 2 .

\section{Cell dimension evaluation}

The skin effective surface diameter was calculated using measurement plastic scale (Polo, India) exactly same of the semi-permeable membrane used in NDDC and FDC. The effective surface area of NDDC was found to be $11.618 \mathrm{~cm}^{2}$ and of FDC was found to be $1.79 \mathrm{~cm}^{2}$. The effective surface area of NDDC is about 10 times more than that of FDC. This could be one of the reasons for the enhanced diffusion of drugs through NDDC.

The drug diffusion studies carried out on different BCS class drugs using FDC and NDDC revealed that mean percentage cumulative drug release was greater in NDDC as compared to FDC. The test of significance showed that the $P$ value of mean percentage cumulative drug release between FDC and NDDC is $<0.05$ (i.e. $P=0.008,0.004$, 0.0001 , and 0.0001 for metronidazole, diclofenac sodium, fluconazole, and sulfadiazine gels, respectively) as shown in Figs. 4-7. This reveals that there is a significant difference in the drug release of all the drugs in FDC and NDDC. It was observed that 0.82 -fold increase in the release of sulfadiazine and 0.75 -fold increase in the release of diclofenac sodium through NDDC as compared to FDC. However, folds increase in the release of fluconazole and 0.65 -fold increase in the release of metronidazole were observed through NDDC as compared to FDC respectively.

The higher percentage drug release in the improved cell is attributed to two factors:

\section{Higher membrane surface area}

This is due to the presence of membrane sac instead of flat membrane, which leads to greater exposure of drug mounted on membrane sac, to the receptor compartment as compared to FDC.

\section{Higher receptor cell volume}

In FDC only 30-100 ml of liquid can be filled in the receptor compartment, while in case of the improved cell, volume of up to 10 times can be used in the receptor compartment. Due to the small volume of liquid in the FDC, equilibrium between the donor and receptor compartments is achieved within a short period of time, and this stops the permeation of drug from donor to receptor compartment. However, in case of the improved cell, due to much higher volume, equilibrium is not reached easily, and drug continues to diffuse very fast.

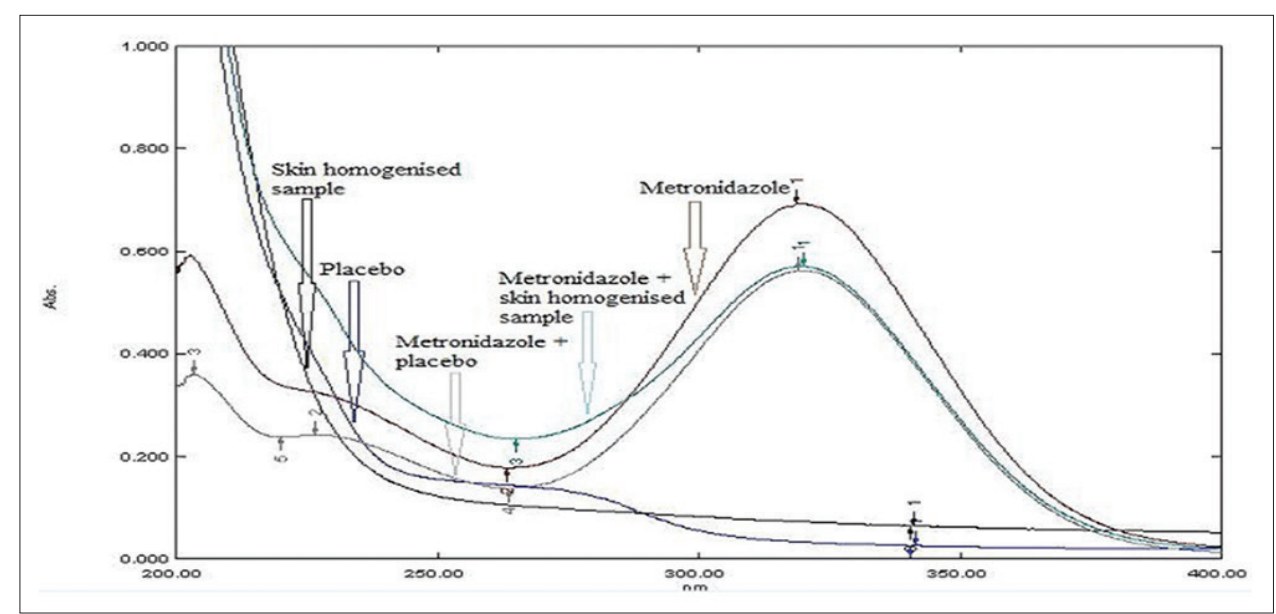

Fig. 8: Overlay spectrum of metronidazole, skin, and placebo 


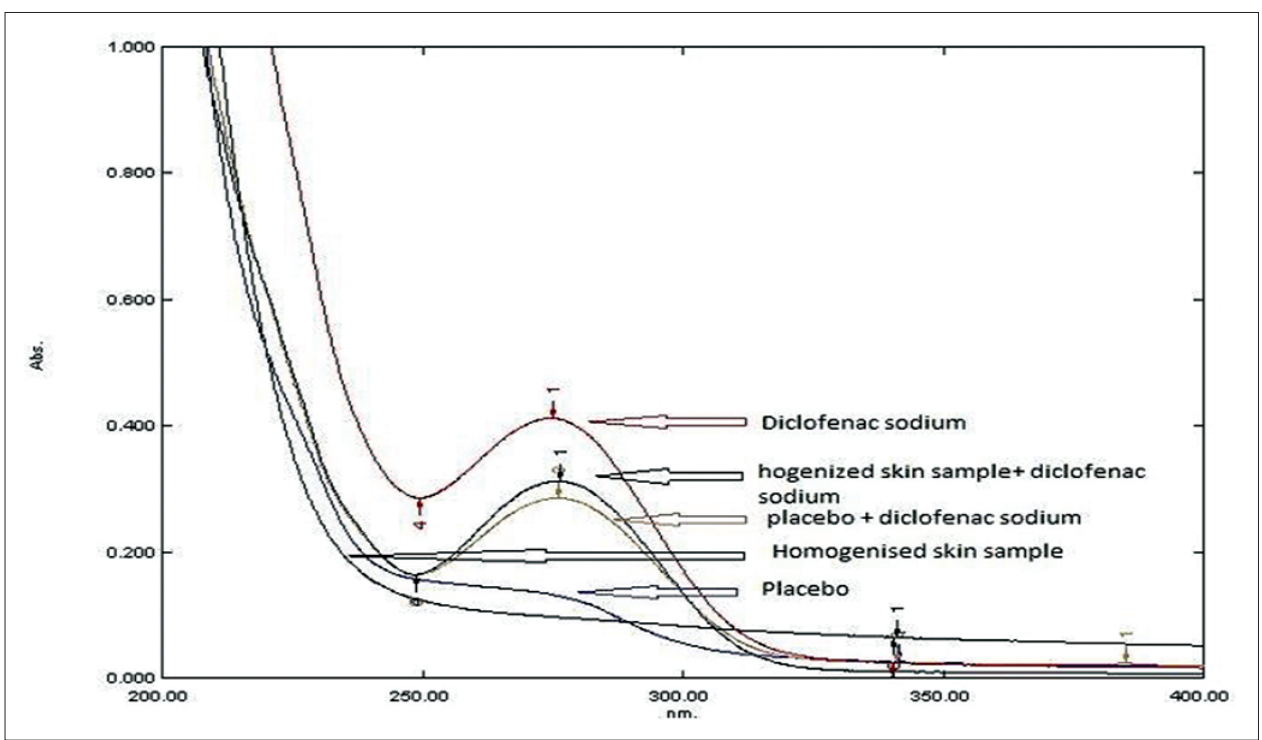

Fig. 9: Overlay spectrum of diclofenac sodium, skin, and placebo

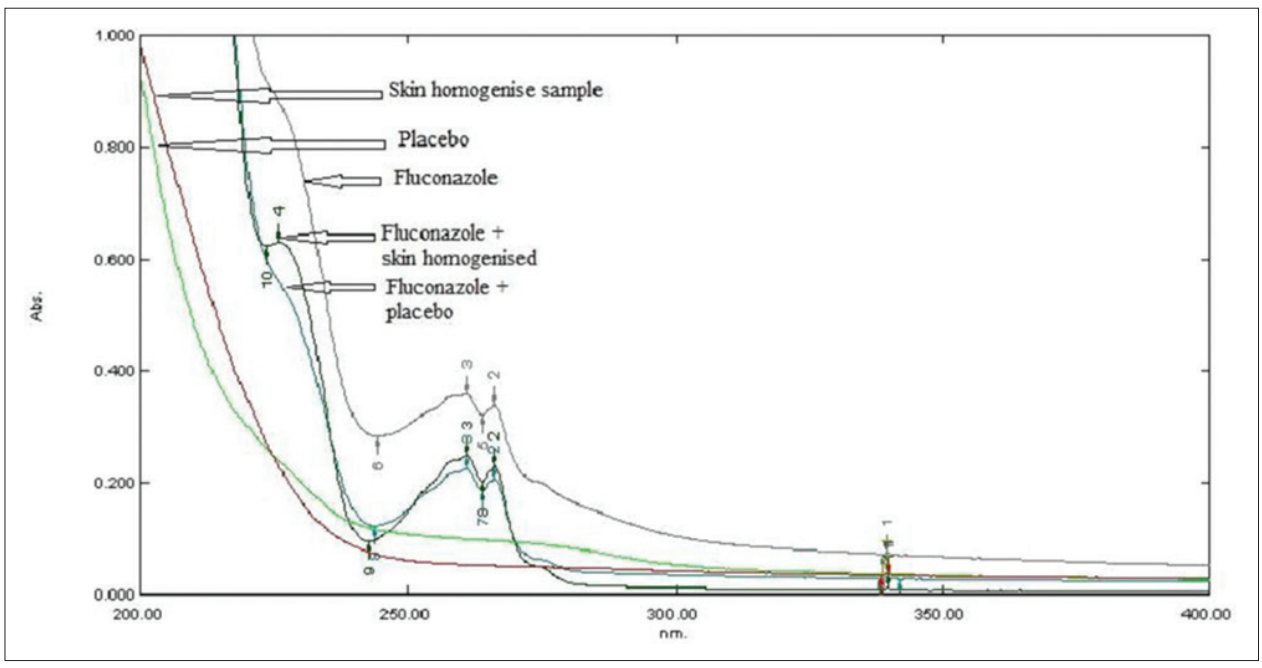

Fig. 10: Overlay spectrum of fluconazole, skin, and placebo

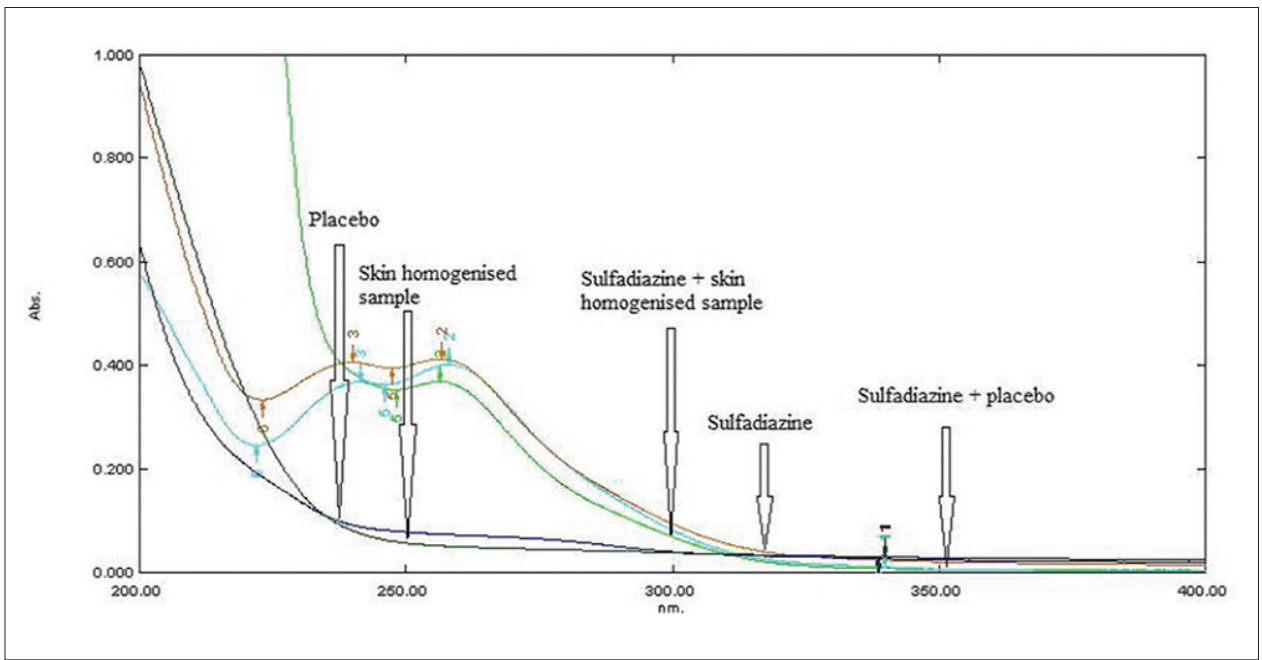

Fig. 11: Overlay spectrum of fluconazole, skin, and placebo 
One of the major problems with FDC has been the high value of variation in the results. This can be attributed to the formation of air bubbles and non-sink conditions in receptor phase due to a limited volume. The problems of lack of reproducibility were experienced in our studies using FDC also.

\section{Specificity studies}

The overlay of spectra of specificity studies of metronidazole, diclofenac sodium, fluconazole, and sulfadiazine are shown in Figs. 8-11. It was observed from the scan that there was no interaction of drug, excipients, and skin. Hence, the study was specific for the estimation of those drugs.

\section{CONCLUSION}

The NDDC has been found to offer certain advantages over the conventional static diffusion cells. During handling the cells were found to be less cumbersome to handle and free from breakability. The release studies were found to be much faster as compared to conventional diffusion cells. The higher release in shorter time was found to give the higher discriminatory ability to the method. No bubble formation was observed during the conduct of the experiments in the NDDC. The reproducibility of results in the term percentage coefficient of variance was found to be considerably better with NDDC as compared to those with FDC. The study will further be extended to evaluate the same parameters of diffusion through various animal membranes to make the use of the cell more comprehensive.

\section{REFERENCES}

1. Reddy PS, Bose PS, Sruthi V, Saritha D. Investigation of kondagogu gum to develop transdermal film of repaglinide. Asian J Pharm Clin Res 2018;11:440-5.

2. Hardainiyan S, Kumar K, Nandy B, Saxena R. Design, formulation and in vitro drug release from transdermal patches containing imipramine hydrochloride as model drug. Int J Pharm Pharm Sci 2017;9:220-5.

3. Franz T. The finite dose technique as a valid in vitro model for the study of percutaneous absorption. Curr Probl Dermatol 1978;7:58-68.

4. Farinha A, Toscano C, Campos R, Bica A, Hadgraft J. Permeation of naproxen from saturated solutions and commercialformulations through synthetic membranes. Drug Dev Ind Pharm 2003;29:489-94.

5. Shah V, Elkins J, Lam S, Skelly J. Determination of in vitro drug release from hydrocortisone creams. Int J Pharm 1989;53:53-9.

6. Siewert M, Dressman J, Brown C, Shah V. FIP/AAPS guidelines to dissolution/in vitro release testing of novel/special dosage forms. AAPS PharmSci Tech 2003;4:6-13.

7. Shah V, Elkins J, Williams R. Evaluation of the test system used for in vitro release of drugs for topical dermatological drug products. Pharm Dev Technol 1999;4:377-85.

8. Bartosova L, Bajgar J. Transdermal drug delivery in vitro using diffusion cells. Curr Med Chem 2012;19:4671-7.

9. Bronaugh RL, Stewart RF. Methods for in vitro percutaneous absorption studies IV: The flow-through diffusion cell. J Pharm Sci 1985;74:64-7.

10. Pendlington RU. Principles and practice skin toxicology. In: Chilcott RP, Price S, editors. In Vitro Percutaneous Absorption Measurements. United Kingdom: John Wiley \& Sons Chichester; 2008. p. 129-47.

11. Yang H, Imbert DC. Inventor; Static Diffusion Cell for Diffusion Sampling Systems. U.S. Patent, Patent No. US 8133721B2; 2011.

12. Mannam R, Yallamalli I. Pharmacokinetic study of matrix membrane moderated transdermal system of bosentan monohydrate. Asian J Pharm Clin Res 2017;10:255-8.

13. Yang H, Imbert DC. Inventor; Static Diffusion Cell for Diffusion Sampling Systems. U.S. Patent, Patent No. US 7470535B2; 2008.

14. Mohammad A. Inventor; Diffusion Cell for Ex - Vivo Pressure - Controlled Trans Corneal Drug Penetration Studies. U. S. Patent, Patent No. US 5789240A; 1998.

15. Joseph MB, Patrick JR, Mark AT. Inventor; Gel Formulations for Topical Drug Delivery. U. S. Patent, Patent No. US 0015715A1; 2002.

16. Castro J, Zhang YS, Lee L. Inventor; Transdermal Diffusion Cell Testing Arrangements and Methods, U. S. Patent. Patent No. US 0120215A1; 2011

17. Sood S, Jain K, Gowthamarajan K. Optimization of curcumin nanoemulsion for intranasal delivery using design of experiment and its toxicity assessment. Colloids Surf B Biointerfaces 2014;113:330-7. 